\title{
PEMANFAATAN LAHAN DAN PENINGKATAN PENDAPATAN MASYARAKAT DENGAN AQUAPONIK DI JATIPULO, TANAH ABANG
}

\author{
Rakhdiny Sustaningrum, Rianita Pramitasari
}

\author{
Universitas Katolik Indonesia Atma Jaya, Jl. Jend. Sudirman No.51, RT.5/RW.4, Karet \\ Semanggi, Kecamatan Setiabudi, Kota Jakarta Selatan, Daerah Khusus Ibukota Jakarta 12930 \\ Email: rakhdiny.s@atmajaya.ac.id
}

\begin{abstract}
ABSTRAK
Penduduk DKI Jakarta masih dianggap sebagai penduduk yang memiliki tingkat kemiskinan dan ketimpangan ekonomi yang akan berpengaruh pada permasalahan kesehatan dan psikologis penduduk dimana daerah Jatipulo menjadi salah satu diantaranya. Kegiatan pelatihan warga yang bertujuan untuk memberikan keterampilan dan pengetahuan yang diharapkan menjadi modal untuk penerapan pola hidup sehat dan meningkatkan taraf hidup. Kegiatan pembekalan dan keterampilan menjadi upaya berupa: 1. Pelatihan bercocok tanam hidroponik 2. Pembekalan pengetahuan dalam usaha 3. Pembekalan pengetahuan pemasaran produk 4 . Pengolahan pascapanen produk. Metode kegiatan dilaksanakan dengan metode presentasi dan pendampingan lapangan selama tiga bulan. Berdasarkan evaluasi dan monitoring yang dilakukan bahwa tanaman hidroponik diterapkan warga dan peduduk secara swadaya berlanjut membuat kolam ikan untuk aquaponik yang hasilnya siap dikonsumsi dan dijual. Kegiatan terkait dengan penggunan bahan sederhana dalam rumah tangga sebagai bahan hidroponik dan pemberian modal bantuan terkait pangan untuk konsumsi sehari-hari dan pendampingan secara konsisten terbukti efektif mengubah pola hidup penduduk.
\end{abstract}

Kata kunci: aquaponik, hidroponik, kewirausahaan, pendapatan

\begin{abstract}
DKI Jakarta residents are considered to have poverty issues and economic inequality that will affect the health and psychological problems, the Jatipulo area, is one of them. Community training activities aim to provide skills and knowledge that are expected to be capital for the application of healthy lifestyles and improve living standards. Provisioning activities and skills into an effort in the form of 1. Training in hydroponic cultivation 2. Provision of knowledge in business 3. Provision of product marketing knowledge 4. Processing post-harvest products. The activity method was finalized in a three-month presentation and field assistance method. Based on the evaluation and monitoring carried out that the hydroponic plants applied by residents and residents independently continue to make fish ponds for aquaponics, the results of which are ready for consumption and sale. Activities related to the use of simple materials
\end{abstract}


in the household as hydroponic materials and the provision of capital assistance related to food for daily consumption and assistance are consistently effective in changing people's lifestyles.

Keywords: aquaponic, entrepreneur, hydroponic, revenue

\section{PENDAHULUAN}

Penelitian yang dilakukan oleh Heltberg (2009) menjelaskan bahwa hubungan antara pertumbuhan ekonomi dan kekurangan gizi anak kronis berpengaruh secara signifikan. Sementara kasus di Indonesia terdapat angka tercatat di BPS menyatakan bahwa tingkat kemiskinan dan ketimpangan di DKI Jakarta periode Maret 2018 yaitu sebesar 3,57 persen atau sebanyak 373.120 orang. Hal ini juga disampaikan oleh Wakil Gubernur Sandiaga Uno bahwa faktor pendorong tingkat kemiskinan di Jakarta disebabkan oleh inflasi (Nibras, 2018), dengan mengkategorikan penduduk miskin sebagai orang dengan pengeluaran $\mathrm{Rp} \quad 578.000$ perbulan setara dengan $\mathrm{Rp} 19.000$ per hari (Renaldi, 2018).

Dampak

kemiskinan

merupakan perkara yang serius dan akan bepengaruh terhadap generasi karena anak-anak dalam kemiskinan memiliki kecenderungan permasalahan kesehatan dan psikologis. Bayi yang lahir dalam kemiskinan dengan asupan gizi yang kurang akan memiliki cacat mental dan mudah sakit. Sementara anak yang dibesarkan dalam kemiskinan akan kesulitan dalam pendidikan dan tumbuh dalam keluarga yang mengalami banyak tekanan daripada kelas menengah karena ketidakpastian keuangan. Ketidakpastian keuangan yang dialami orang tua dapat menjadi terlalu menghukum, lebih menuntut yang diikuti oleh penghinaan, ancaman, dan hukuman fisik.

Di Indonesia, 37,2\% anak di bawah usia lima tahun terhambat dan kesadaran masyarakat tentang masalah ini rendah Beban ganda gizi buruk (Double Burden Malnutrition, DBM) sudah ada di tingkat populasi di Indonesia, dengan kurang gizi dan kekurangan gizi terlihat pada anakanak dan orang dewasa dari semua tingkat pendapatan sepanjang hidup saja. Masalah gizi utama di Indonesia adalah bahwa 36\% anak kecil terhambat (World Bank, 2013).

Salah satu cara untuk membantu perekonomian penduduk yaitu dengan memberikan kemandirian usaha yang didasarkan pada adanya pembekalan ilmu berwirausaha yang diharapkan dapat menumbukan jenis usaha kecil ditingkat masyarakat. Data pada Kementerian Koperasi dan Usaha Kecil Menengah mengemukakan jumlah UMKM tahun 2019 mencapai 99,7 persen dengan sumbangan terhadap PDB (product domestic bruto) mencapai 60,34 persen. Sementara kontribusi terhadap total tenaga kerja sebesar 97 persen. Oleh karena itu upaya pembekalan ilmu melalui kegiatan pengabdian yang dilakukan di Jatipulo, Tanah Abang, terletak di pinggiran kereta stasiun kereta Tanah Abang dan bantaran kali. 
Latar belakang ekonomi masyarakat tinggal berdempetan dan bekerja sebagai pengemudi ojek online, pemulung, penjaga keamanan, pedagang kaki lima, dan ibu rumah tangga. Rata-rata tingkat pendapatan masyarakat mencapai $\mathrm{Rp} 500.000,00$ yang tidak cukup untuk memenuhi kebutuhan hidup sehari-hari. Konsumsi harian penduduk adalah mie instan dan nasi tanpa asupan gizi memadai.

Sasaran peserta mitra pengabdian yaitu pada RW 08 Kelurahan Jatipulo, Jakarta Barat. Secara administratif Jatipulo merupakan kelurahan yang terdaftar pada Kecamatan Palmerah, Jakarta Barat dengan luas daerah sebesar $0.55 \mathrm{~km}^{2}$. Daerah ini berbatasan kelurahan ini memiliki penduduk sebesar 33.517 jiwa. Kelurahan ini berbatasan dengan Jalan Tomang Raya di sebelah utara, Jalan Letjen S. Parman di sebelah barat, Kali Banjir Kanal di sebelah timur dan Jalan Bidara dan Cempaka di sebelah selatan.

Mayoritas penduduk merupakan suku asli Betawi yang telah lebih dari 30 tahun menetap dan pendatang dari daerah yang pernah terkena dampak penggusuran dipinggir rel kereta api oleh pemerintah daerah Jakarta. Pada tahun 2013, jumlah penduduk tetap sebanyak 3.595 orang dan penduduk musiman sebanyak 785 orang dengan rentang usia produktif penduduk pada 14-65 tahun. Selama kegiatan dan kunjungan berlangsung, untuk mempermudah akses ke RW 08 Jatipulo tim berhenti di Dipo Lokomotif Tanah Abang dan menyebrang jembatan Banjir Kanal.
Dengan melihat tingkat pendapatan masyarakat yang dibawah dari Upah Minimum Regional DKI Jakarta, kegiatan ini ditujukan memberikan keterampilan dan pengetahuan yang diharapkan menjadi modal untuk penerapan pola hidup sehat dan meningkatkan taraf hidup.

\section{METODE}

Dalam pelaksanaan kegiatan lebih menitikberatkan pada mencari permasalahan sosial di masyarakat yang secara umum mencakup masalah kesehatan dan kemiskinan. Kedua hal ini menjadi dasar untuk menentukan jenis kegiatan yang menarik masyarakat dan dapat memberikan nilai lebih.

\section{Mencari Permasalahan Sosial}

Awal penentuan dari lokasi didasari dari penugasan mata kuliah Kewirausahaan Sosial yang dilaksanakan oleh mahasiswa dengan melaksanakan kunjungan survey ke lokasi pada bulan Maret 2018 dengan target mitra yang memiliki permasalahan sosial berupa kemiskinan dan kesehatan. Pada survey yang dilaksanakan, mahasiswa mewawancara ketua RT 04/RW 08. Warga Jatipulo berpendapatan dibawah UMR namun sudah melakukan kegiatan Bank Sampah sejak tahun 2013 yang terkumpul dihargai Rp 1000 per kg. Namun jumlah uang yang terkumpul masih dinilai belum cukup untuk memenuhi kebutuhan sehari-hari.

Oleh karena itu, mahasiswa menawarkan adanya kegiatan 
penyuluhan dan adanya sambutan hangat dan dukungan dari warga dan mendorong kegiatan pengabdian masyarakat dengan memanfaatkan bahan secara sederhana. Kegiatan penyuluhan Hidroponik atau Aquaponik menjadi salah satu topik yang disetujui.

Dalam kegiatan ini, panitia bekerja sama dengan Badan PKP Provinsi DKI Jakarta dalam memberikan penjelasan mengenai sistem Hidroponik/Aquaponik dan penambahan proses pengelolaan pasca produksi menjadi produk olahan yang menggunakan sayuran hidroponik yang bekerja sama dengan Fakultas Teknobiologi.

Hidroponik adalah budidaya menanam dengan dengan memanfaatkan air tanpa menggunakan tanah dengan menekankan pada pemenuhan kebutuhan nutrisi bagi tanaman. Kebutuhan air pada hidroponik lebih sedikit daripada kebutuhan air pada budidaya dengan tanah. Hidroponik menggunakan air yang lebih efisien, jadi cocok diterapkan pada daerah yang memiliki pasokan air yang terbatas. Teknik hidroponik banyak dilakukan dalam skala kecil sebagai hobi dikalangan masyarakat Indonesia (Haryanto \& Nurwijayanti, 2018). Prinsip dasar hidroponik adalah upaya memberikan unsur hara atau nutrisi yang diperlukan tanaman. Melalui teknik ini akan lebih banyak tanaman yang dapat dibudidayakan dalam satuan ruang yang sempit. Bahkan tanaman akan tumbuh lebih produktif meski tanpa media tanah (Oktarina \& Purwanto, 2009)

\section{Sosialisasi Kegiatan}

Kegiatan sosialisasi diadakan secara terbuka dengan metode presentasi dan praktek yang menggunakan peralatan. Kegiatan sosialiasasi dihadiri oleh 25 orang Ibu PKK. Pada sesi pertama, peserta diberikan dasar bagaimana berwirausaha yang terfokus pada komponen utama ketika berusaha. Paparan diberikan berupa Business Model Canvas (BMC) yang telah diterjemahkan menjadi bahasa yang lebih dipahami oleh peserta dan diberikan contoh sesuai dengan keseharian masyarakat seperti bagaimana memulai usaha dalam berjualan kue atau membuka ketering. Dasar pemberian matrei BMC merupakan dasar dari perencanaan usaha bisnis, mencakup elemen dasar dalam menjalankan bisnis yang digunakan oleh pengusaha pada umumnya.

Dalam sesi ini pula, materi yang diberikan dapat ditanggapi oleh ibu PKK lebih mudah karena mereka sudah mengerti yang terjadi pada keseharian. Diskusi terbuka dan interaksi dalam sesi ini menjadi aktif ketika salah satu peserta membagikan pengalamanya dalam menjalankan usaha dan menyadari bahwa komponen dalam BMC membuat dia semakin mengerti dan harus lebih memfokuskan dan dapat memperbaiki kesalahan yang ada. Hal yang disampaikan contohnya itu pentingnya pencatan komponen Biaya pada elemen BMC, yaitu cost structure atau struktur biaya. Pelatih memberikan gambaran akan rincian biaya-biaya yang dikeluarkan baik tercatat maupun tidak tercatat. Hal ini 
menyadarkan bahwa dalam kesehariannya Ibu PKK cenderung tidak menyadari pengeluaran biaya dan tidak menghitung cermat.

Pada sesi kedua, peserta dibekali bagaimana dasar dalam pemasaran dengan materi marketing mix atau Bauran Pemasaran. Materi ini diberikan dan disajikan secara sederhana. Hasil keluaran dalam sesi ini diharapkan Ibu PKK dapat memasarkan produknya lebih aktif dan terperinci. Beberapa masalah yang sering kali timbul dalam penjualan sehari-hari adalah tunggakan tetangga dalam membeli, keinginan untuk membuat produk yang dijual terlihat menarik, menyikapi pelanggan dan menyelesaikan masalah, cara memanfaatkan hubungan relasi, bagaimana menentukan harga produk/barang dagangan, dan bagaimana agar pelanggan

Pelatih memberikan dasar teori dalam memberikan merek pada produk agar terkesan lebih rapi dan "layak jual", memberikan alternatif jalur penjualan melalui online, memberikan dasar bersikap dalam menanggapi pelanggan, memberikan strategi penentuan harga dan menghemat biaya untuk meningkatkan keuntungan, dan bagaimana menciptakan customer loyalty dengan menggunakan promosi atau diskon.

Pada sesi ketiga diberikan pembekalan mengenai pengetahuan Hidroponik atau Aquaponik. Sesi ini dipaparkan oleh Ibu Ikrar Sukowati yang merupakan penyuluh lapangan dari Dinas Pertanian Provinsi DKI Jakarta. Ibu Ikrar yang didampingi oleh asisten penyuluh mengisi sesi dengan memberikan paparan yang diberikan pula contoh praktek dan tanaman dalam bentuk hidroponik.

Peragaan dalam sesi ini mengundang antusias peserta karena terlihat menarik dan dapat diterapkan di kehidupan sehari-hari dengan penggunaan bahan dan hasil tunggu panen dengan minimal 2 minggu dan maksimal 3 bulan.

Pada sesi keempat diberikan berupa pengolahan hasil pangan yang diberikan oleh fakultas teknobiologi dengan pengolahan eskrim yang berbahan dasar bayam. pemberian materi dan pengetahuan dalam pembuatan eskrim ditujukan pengolahan sayuran akan memberikan nilai lebih atau added value terhadap produk sayuran bayam. Tanaman bayam diolah menjadi eskrim yang hasilnya dapat dikonsumsi secara swadaya atau dijadikan barang dagangan. pada sesi ini penduduk melakukan praktek dalam pembuatan eskrim dengan bahan-bahan yang disediakan oleh panitia.

Kegiatan ini ditutup pada pukul 12.30 dengan membagikan makan siang dan snek ke penduduk dan ucapan terima kasih oleh ketua PKK atas kehadiran panitia dalam pembekalan ilmu yang diberikan oleh fasilitator Atma Jaya dan dukungan dari Dinas Pertanian Provinsi Jakarta.

\section{HASIL DAN PEMBAHASAN}

\section{Pembekalan Ilmu dan Keterampilan}

Human capital (sumber daya manusia) didefiniskan sebagai sebagai keterampilan dan pengetahuan yang diperoleh individu melalui investasi 
sekolah, pelatihan di tempat kerja, dan jenis pengalaman lainnya (Becker, 1964). Pengetahuan bermanfaat untuk memperoleh sumber daya penting lainnya seperti modal finansial dan fisik (Brush, et al., 2001). Oleh karena itu Unger et al. (2011) mengasumsikan bahwa pemilik dengan sumber daya manusia yang lebih tinggi harus lebih efektif dan efisien dalam menjalankan bisnis mereka daripada pemilik dengan sumber daya manusia yang lebih rendah.

Tidak hanya itu, dalam argumen yang sama, suatu perusahaan dapat memperoleh keunggulan kompetitif jika ia memiliki kemampuan yang lebih besar (Barney \& Wright, 1998). Oleh karena itu, intervensi dalam kewirausahaan pelatihan kreativitas dan inovasi adalah kebutuhan untuk bertahan hidup, pertumbuhan yang berkelanjutan dan kemakmuran bisnis (Sarri, Bakouros, \& Petridou, 2010).

Di Indonesia, salah satu sektor yang diatur dalam Undang-Undang Nomor 7 Tahun 2014 adalah pemberdayaan usaha mikro, kecil dan menengah. Berdasarkan Bab X Pasal 73 ayat (2) Undang-Undang Nomor 7 Tahun 2014, pemberdayaan usaha mikro, kecil dan menengah yang dilakukan oleh Pemerintah dan/atau Pemerintah Daerah dapat berupa:
a. Pemberian Fasilitas
b. Insentif
c. Bimbingan Teknis
d. Akses dan/atau
Permodalan
e. Bantuan Promosi
Pemasaran.
Upaya untuk membantu

masyarakat dalam sisi ekonomi dengan meningkatkan pendapatan salah satunya memberikan bekal pengetahuan. Bekal pengetahuan ini diharapkan dapat menjadi modal masyarakat untuk mendirikan usaha atau dapat digunakan untuk menopang perekonomian secara swadaya.

Pembangunan suatu usaha, baik skala kecil, menengah, atau besar, para pengusaha harus merencanakan setiap elemen bisnis yang internal maupun eksternal perusahaan. elemen bisnis ini saling berpengaruh pada setiap keputusan yang diambil oleh pengusaha, oleh karena itu elemen tersebut harus dipaparkan secara garis besar agar pengusaha tahu betul yang menjadi elemen penting dalam usahanya, seperti produk, pelanggan, proses bisnis, pemasaran, pengeluaran, supplier, dan sumberdaya.

BMC merupakan salah satu metode yang digunakan oleh pengusaha dalam membuat secara jelas yang terkait dengan semua komponen bisnis. BMC ini mulai dipopulerkan oleh Alexander Osterwalder \& Yves Pigneur dalam terbitan buku Business Model Generation pada tahun 2010 yang dimana Bisnis Model ini diartikan sebagai gambaran dasar pemikiran bagaimana suatu organisasi menciptakan, memberikan, dan menangkap nilai (value). Buku ini menjelaskan bagaimana sembilan elemen blok terdiri dari value preposition, customer segment, channel, revenue, key activities, key resources, key partner, dan cost merupakan bagianbagian dari unsur bisnis. 
Kegiatan pengabdian yang diadakan kali ini, pelatihan yang diberikan berupa BMC kepada masyarakat dengan hasil bahwa penduduk dapat memahami pentingnya bagian dalam usaha agar lebih cermat dalam menjalankan usaha. pemberian materi BMC diberikan dengan bahasa ringan dan sederhana agar lebih mudah dipahami. Sesi selama 45 menit disampaikan dengan diskusi secara terbuka dan masyarakat dapat mengemukakan pendapat dan permasalahan yang ada pada keseharian.

Berdasarkan hasil paparan, penduduk banyak mengeluhkan adanya kesulitan dalam pencatatan biaya atau pengeluaran dalam usaha, bagaimana membuat produk yang unik dari pada pesaing, jumlah pembeli yang biasa, menambah usaha. dalam menjawab hal ini, pelatih bertanya mengenai permasalahan yang terjadi terlebih dahulu dan kemudian memberikan arahan disertai dengan contoh pada penerapannya di masyarakat lain. misalnya dalam pencatatan pembiayaan, pelatih memberikan rincian contoh biaya yang tercantum dalam bisnis kemudian memberikan contoh pencatatan pembiayaan.

Sementara pada keunikan produk, peserta diberikan arahan bagaimana memberikan keunggulan produk tidak hanya pada segi rasa, tetapi pada tampilan, kebersihan, meningkatkan kandungan gizi atau memberikan tambahan nilai manfaat pada makanan, atau dengan melakukan perubahan pada tampilan produk dengan memberikan merk agar mudah diingat oleh pelanggan.

Pencatatan permasalahan dalam kegiatan pelaksanaan bisnis rumah tangga, pelatih menemukan permasalahan bahwa penduduk dapat diberikan pelatihan bagaimana mengelola keuangan rumah tangga agar keuntungan yang diterima dari bisnis dapat diolah tidak hanya untuk menambah penghasilan rumah tangga, namun dapat memberikan manfaat untuk taraf hidup berupa pendidikan anak. hal ini dapat menjadi rencana kegiatan lanjutan pada program pengabdian masyarakat selanjutnya.

Setelah memberikan pelatihan dalam komponen usaha, dalam pengabdian ini juga menitikberatkan bagaimana meningkatkan penjualan melalui pemasaran yang menggunakan dasar teori berupa marketing mix (4P's, yaitu product, price, place, promotion). materi pemahaman $4 \mathrm{P}^{\prime} \mathrm{s}$ ini diberikan secara sederhana dengan pendekatan permasalahan sehari-hari untuk tingkat usaha kecil. Marketing mix merupakan teori yang dikemukan oleh Jerome E. McCarthy.

Pelatih memberikan bekal berupa standar produk dalam memasarkan produknya seperti memberikan merek, memberikan penjelasan singkat penggunaan atau pemanfaatan sosial media untuk memperluas pemasaran atau memberikan penjelasan penggunaan salah satu marketplace dalam menjual produk atau menyebarkan informasi penjualan melalui grup chat.

Pada bagian ini ibu PKK sudah memiliki telepon gengam yang dapat mengunduh langsung beberapa aplikasi pendukung penjualan seperti 
Tokopedia dan Bukalapak. pelatih secara umum juga memberikan contoh nyata akan ada beberapa penjual usaha kecil yang menggunakan aplikasi online berdampak pada meningkatnya penjualan yang dapat menjangkau seluruh Indonesia.

Sistem aquaponik memang tidaklah selalu sempurna namun sistem ini dapat membantu kita untuk menghemat air lahan dan energi dengan cara yang benar sekaligus menghasilkan produk makanan yang bermutu baik untuk dikonsumsi secara pribadi maupun untuk tujuan komersil.

Pada kegiatan pengabdian dalam pembekalan hidroponik bekerja sama dengan Dinas Pertanian yang memberikan pelatihan dan pengenalan selama 2 jam yang dihadiri oleh dua pendamping. Pada sesi ini pendamping lapangan membawa contoh alat dan peralatan yang digunakan dalam hidroponik/aquaponik baik dalam kegiatan penanaman maupun peralatan hidroponik dapat memanfaatkan sisa rumah tangga sehari-hari seperti plastic aqua gelas, busa, sumbu kompor minyak, pipa pralon talang air, baskom rumah tangga.

Sesi ini pendamping memberikan paparan dalam presentasi pengertian, cara pemanfaatan hidroponik, pelaksanaan dan perawatan. Pembimbing mempraktekkan proses hidroponik dalam wadah plastik.

\section{Evaluasi Kegiatan}

\subsection{Evaluasi Tahap Pertama}

Dalam kegiatan ini dilakukan evaluasi berjarak 1 bulan setelah dari kegiatan sosialisasi yang dilaksanakan dimana fasilitator melakukan kunjungan ke lokasi untuk melihat penerapan yang sudah dilakukan oleh warga setelah sosialisasi. Pada tahap ini bertujuan untuk melihat penerapan yang dilakukan oleh warga setelah sosialisasi dilakukan.

Pada kunjungan evaluas pertama, tim menemukan bahwa beberapa warga baru menerapkan sistem hidroponik seadanya dengan menggunakan botol aqua bekas sebagai media tanam dan sisa kaleng makanan siap saji,

Dari penerapan kegiatan ini, ternyata didapatkan bahwa hanya 5 Ibu PKK yang menerapkan pola tanam hidroponik dengan menggunakan tanaman bayam dan kangkung. Tanaman ini kemudian di konsumsi secara swadaya di rumah tangga.

Pada kegiatan ini kendala yang dihadapi yaitu:

1. Kurangnya keinginan yang kuat oleh Ibu PKK lain dalam menerapkan pola hidroponik di rumah, namun konsistensi dilakukan oleh 2 peserta pelatihan, yaitu Bapak Uus dan Bapak Bernard

2. Pengumpulan perlengkapan dinilai memberatkan warga karena botol umumnya akan dijual kembali di bank sampah.

3. Kurangnya keuletan dan kesabaran penduduk dalam mengusahakan hidroponik, tanaman yang gagal tanam tidak diteruskan

4. Walaupun kegiatan hidroponik hanya dilakukan tidak semua peserta pelatihan, namun mereka 
yang tidak melakukan hidroponik, merasakan adanya menafaat pengetahuan dalam pemasaran dan pendirian bisnis yang menjadi materi pelatihan. Dua orang Ibu PKK yang menjadi peserta pelatihan menerapkan pola pemasaran di usaha warteg dan gorengan milik mereka dan satu orang Ibu PKK mencoba memulai usaha bisnis baru mencoba usaha keripik balado. Berdasarkan hasil wawancara, pelatihan hidroponik dan pelatihan eskrim bayam bukan berarti tidak bermanfaat bagi mereka, hanya saja mereka lebih memilih usaha yang yang sudah ada untuk ditekuni dan salah satunya memang pernah memiliki pengalaman bekerja di restoran sehingga memilih untuk mencoba untuk membuka usaha di keripik balado.

Salah satu warga yang memang konsisten untuk melaksanakan kegiatan hidroponik sudah menjalankan kegiatan hidroponik dan sedang mengembangkan kolam ikan nila untuk dapat dilanjutkan ke sistem aquaponik. peralatan pipa hidroponik yang diterima merupakan penerapan hidroponik kelas kewirausahaan tahun Genap 2017/2018 yang melaksanakan kegiatan hidroponik untuk warga. Tim memberikan modal berupa bibit dan peralatan sederhana untuk dapat digunakan oleh pekarangan warga yang terbatas.

Pada kunjungan evaluasi ini pak Uus sedang dalam tahap membangun kolam ikan yang nantinya akan digunakan untuk Aquaponik. Tahap pertama evaluasi didapati bahwa penduduk melakukan aquaponik secara bertahap, yaitu dengan memulai dengan kegiatan hidroponik. Kolam ikan yang dibangun menggunakan sisa lahan dengan ukuran $3 \mathrm{~m} \times 2 \mathrm{~m} \times 1,5 \mathrm{~cm}$. Kolam ikan ini nantinya akan digunakan untuk mengaliri tanaman hidroponik. Sementara, pengaliran hidroponik masih dilakukan secara manual yaitu dengan melakukan pengecekan debit air dalam pipa. Air dapat ditambahkan ke dalam pipa jika debit air berkurang.

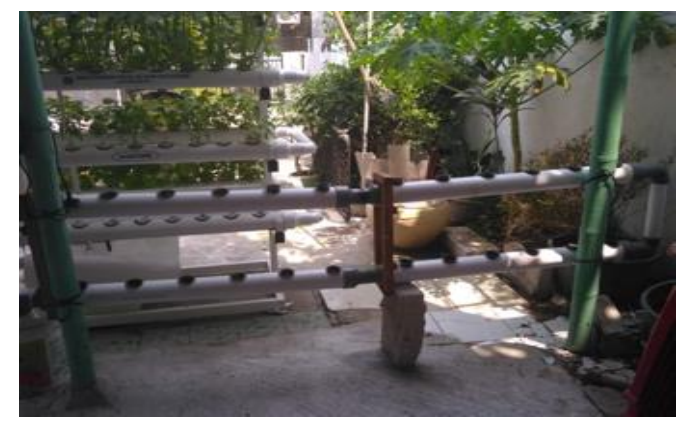

Gambar 1. Pipa hidropionik

\subsection{Evaluasi Tahap Kedua}

Evaluasi tahap kedua dilaksanakan 2 minggu setelah evaluasi tahap pertama yaitu pada tanggal Pada evaluasi ini bertujuan untuk melihat konsistensi penduduk dalam menerapkan kegiatan yang telah diajarkan, adanya kelanjutan pola konsumsi tanaman yang sudah ditanam, melaksanakan keberlanjutan penanaman hidroponik, dan memulai usaha untuk menerapkan pola penanaman hidroponik.

\section{Solusi Kegiatan}

Beberapa permasalahan yang muncul dari kegiatan ini terbagi menjadi dua bagian kegiatan, yaitu 
1. Tidak semua ibu PKK yang menjadi peserta kegiatan menerapkan pelatihan hidroponik dikarenakan kurangnya minat dan keuletan warga dikarenakan mereka membutuhkan uang per hari

Solusi:

- Memberikan akses kepada warga agar tim pengabdian Atma Jaya dapat terus dikontak melalui whatsapp atau telepon jika terdapat kendala dalam menjalankan usaha. Hal ini merupakan bimbingan agar program terjadi secara kontinyu dan tidak bersifat sekali waktu

- Memberikan modul Pendirian Usaha dan Pemasaran sebagai panduan penduduk bagi yang hendak membuka usaha diluar dari hidroponik atau eskrim bayam

2. Kurangnya tenaga kerja muda yang membantu pembangunan dan pemeliharaan hidroponik dikarenakan penduduk berusia muda memilih untuk bekerja menjadi pedagang keliling, pegawai toko, pekerja bangunan, atau pengemudi ojek online.

Solusi: tetap melakukan pemantauan terhadap perkembangan hidroponik menjadi aquaponik dan memberikan bimbingan pemasaran agar keberhasilan kegiatan dapat menjadi contoh dan referensi bagi penduduk lainnya

\section{KESIMPULAN}

Pada kegiatan pembinaan masyarakat merupakan salah satu kegiatan yang sebenarnya membantu memecahkan permasalahan sosial, oleh karena itu kegiatan ini mensasarkan pada warga Tanah Abang, yaitu warga Jatipulo. Warga Jatipulo yang menjadi kegiatan lanjutan karena manfaat yang diterima oleh warga menjadi bermanfaat dalam meningkatkan pendapatan penduduk. Kegiatan ini memberikan pembekalan berupa perencanaan usaha, pemasaran, pelatihan hidroponik/aquaponik, dan pengolahan eskrim bayam sebagai pasca panen dari produk.

Masyarakat menerapkan hidroponik secara sederhana dan ada pula yang menerapkan pemasaran dan memulai usaha sebagai minat penduduk untuk membuka usaha.

\section{DAFTAR PUSTAKA}

Barney, J. B., \& Wright, P. M. 1998. On Becoming a Strategic Partner: The Role of Human Resources in Gaining Competitive Advantage. Human Resource Management, 37 (1), 31-46

Becker, G. S. 1964. Human Capital. New York: Columbia University Press.

Brush, C. G., Greene, P. G., \& Hart, M. M. 2001. From initial idea to unique advantage: the entrepreneurial challenge of constructing a resource base. Academy of Management Executive, 15, 64-78.

Haryanto, D. \& Nurwijayanti, K. N. 2018. imulator Sistem Pengairan Otomatis Tanaman Hidroponik 
Dengan Arduino. Jurnal Teknik Elektro (TESLA), 20 (2), 131-139.

Heltberg, R. 2009. Malnutrition, Poverty, And Economic Growth. Health Economics, 18, 77-88.

Jakarta, D. K. 2016. Profil Kesehatan Provinsi DKI Jakarta tahun 2016. DKI Jakarta: Dinas Kesehatan Provinsi DKI Jakarta.

Oktarina \& Purwanto, B. E. 2009. Responsibilitas Pertumbuhan dan Hasil Selada (Lactuca sativa) secara Hidroponik terhadap Konsentrasi dan Frekuensi Larutan Nutrisi. Agritrop Jurnal Ilmu-ilmu Pertanian , 125-132.

Raharjo, B. 2018. Anies Sebut Pendapatan 3 Juta Warga DKI di Bawah Rp 1 Juta, Ini Kata BPS Republika

Online: https://www.republika.co.id/berita/n asional/jabodetabeknasional/18/01/07/p26zwb415anies-sebut-pendapatan-3-jutawarga-dki-di-bawah-rp-1-juta-inikata-bps

Tobing, I. S. 2005. Dampak Sampah Terhadap Kesehatan Lingkungan dan Manusia. http://www.academia.edu/28857245 /DAMPAK_SAMPAH_TERHAD AP_KESEHATAN_LINGKUNGA N_DAN_MANUSIA
Sarri, K. K., Bakouros, I. L., \& Petridou, E. 2010. Perspective on Practice: Entrepreneur Training for Creativity and Innovation. Journal of European Industrial Training, 34 (3), 270-288.

Statistik, B. P. 2017. Statistik Lingkungan Hidup di Indonesia 2017. Retrieved 11 22, 2018, from The United Nations Statistics Division (UNSD): https://unstats.un.org/unsd/environ ment/Compendia/Statistik\% 20Ling kungan \%20Hidup\%20Indonesia\% 2 02017.pdf

Unger, J. M., Rauch, A., Frese, M., \& Rosenbusch, N. 2011. Human capital and entrepreneurial success: A meta-analytical review. Journal of Business Venturing , 26, 341-358

World Bank. 2013. The Double burden of Malnutrition in Indonesia. Jakarta: World Bank.

World Bank. 2018. The World Bank In Indonesia. Retrieved 10 22, 2018, from World Bank: https://www.worldbank.org/en/coun try/indonesia/overview 